\title{
A Unified Curriculum for Information Science
}

\begin{abstract}
Discussions relating to the identification of courses and the development of curricula for the information science field cannot yield meaningful results unless the conceptual framework of the field is first delimited and its basic segments defined. Starting with the current ASIS definition of information science, an analysis is made of the rationale of current thinking relevant to the conceptual boundaries and intellectual content of the field. Information science is analyzed to be comprised of the segments of: 1) Conceptualization, 2) Storage/Transmission, and 3) Utilization. Two of the segments are shown to be based on subjective notions which can be investigated, for the most part, through the employment of statistical and normative survey methodology. One of the segments is shown to be susceptible to the application of rigorous research methodology capable of yielding adequate empirical proof. Since all three segments form integral parts of the field, they need to be fully represented in the information science curriculum.
\end{abstract}

$\mathrm{T}$

HERE HAVE BEEN numerous opportunities to read and hear papers addressing themselves to problems relevant to the development of information science curricula. However, it is essential for all to reconsider the fundamental notions inherent in the definition of our occupational field. Discussions relating to curricula development, course identification, and similar topics will lead nowhere unless we can first delimit and define the basic boundaries and segments of our field.

Such delimitation might well begin with the current definition of informa-

Dr. Klempner is Associate Professor of Library Science in the State University of New York at Albany. This paper was presented at the Curriculum Committee Workshop, American Society for Information Science, September 25-29, 1968, at the University of Pittsburgh. tion science, as publicized and disseminated by the President of ASIS (see Robert Taylor's letter of December 1, 1967, addressed to the entire membership of the American Society for Information Science) and which, with slight revision, has been printed and distributed in ASIS brochures.

"As a discipline," reads the definition, "information science investigates the properties and behavior of information, the forces governing the transfer process, and the technology necessary to process information for optimum accessibility and use." The ASIS definition further elaborates that, as an interdisciplinary field, information science is "derived from or related to mathematics, logic, linguistics, psychology, computer technology, operations research, librarianship, the graphic arts, communications, management, and similar fields" (emphasis supplied). 
Quite obviously, as an interdisciplinary field, information science seems to have few limitations. Is information science then a discipline? Is information science then a science? At conferences held at the Georgia Institute of Technology in 1961 and 1962, information science was, indeed, defined as "the science that investigates the properties and behavior of information, the forces governing the flow of information, and the means of processing information for optimum accessibility and usability."1

The terms properties and behavior of information, forces governing the transfer process, forces governing the flow of information, technology necessary, or means necessary to process information are frequently present in most definitions of information science. What is it that we mean when we say that we are going to investigate the properties and behavior of information? Does information have properties? What is information? What is it that we are studying? Is information some elemental essence which, to use one published allusion, ${ }^{2}$ can be squeezed out of recorded discourse like water from a sponge? Having achieved this miracle, do we then button-up our laboratory coats, arrange the pipettes, retrieve our Bunsen burners and start studying the properties of information? Can information be separated from recorded discourse, i.e., from documents, from librarianship or, for that matter, from the subjective and, consequently, continuously changing judgments of human beings?

In a paper initially presented at the 1967 ADI annual meeting, Frederick B. Thompson eloquently developed the view that "the organization is the infor-

\footnotetext{
${ }^{1}$ Conference on Training Information Specialists, Georgia Institute of Technology, October 1961 and April 1962. Proceedings. p. 115.

${ }^{2}$ Robert A. Fairthorne, "Use and Mention' in the Information Sciences," in Symposium on Education for Information Science, Warrenton, Virginia, September 7-10, 1965. Proceedings (Washington, D.C.: Spartan Books, 1965), p. 10.
}

mation." ${ }^{3}$ This view, it might seem, can be expanded to mean that the product of conceptualization is information. Webster defined "conceptualization" as "the act or process of interpreting a mental image of an action or thing," and the term "concept" was defined as "the mental image formed by generalization from particulars." When we engage in the process of conceptualization, we are in essence carrying out a subjective process. What we are doing is selecting and organizing particular elements out of our current experience and linking these elements with others that are distant in time and space. It is only after this process of imposing organization, of conceptualizing what at first were bits and pieces of unrelated data, that we feel informed. The resultant concept or concepts may be subject to additional analysis and empirical proof and may, or may not, fit into accepted scientific or humanistic theory.

Notwithstanding the degree of objectivity of the resultant concept or pattern of concepts, the fact remains that the process of conceptualization is a subjective process and that the product of this subjective process, an abstraction derived from the subjective selection and imposition of organization, certainly ought not to be evaluated by the information scientist for its degree of objectivity. Perhaps this is what Yovits and Ernst had in mind when they stated that "information is a relative quantity and cannot be defined except in terms of a specific situation with a specific set of observable actions." 4 Thus, when we say that as a discipline, "information science investigates the properties and behavior of information and the forces gov-

\footnotetext{
${ }^{3}$ Frederick B. Thompson, "The Organization Is the Information," American Documentation, XIX (July 1968), 305-308.

${ }^{4}$ M. C. Yovits and R. L. Ernst, Generalized Information Systems: Some Consequences of Information Transfer (Columbus, Ohio: Department of Computer and Information Science, Ohio State University, September 15,1968 ), p. 19.
} 
erning the transfer process,"-which properties, what behavior, which forces are we investigating? Are we investigating physical properties?-physical behavior?-physical forces? Can we formulate universal laws based on subjective interpretation of data and unique personal experience?

\section{The Conceptualization Segment}

It is essential for us to recognize and accept the conclusion that at least one segment of information science, that segment which is here being labeled the Conceptualization Segment, is based on subjective notions. It entails what in Ranganathan's terminology may be described as the entering of the idea plane; it calls for the creation of a class, the establishment of relationships between the newly conceptualized class with what, in man's subjective judgment, comprises the totality of his universe. As information scientists, as librarians, as classificationists, as information specialists, we have a direct interest in the process of conceptualization. It is incumbent upon us to study this process and apply it in our own field. Activities in information science employing the conceptualization process may be said to include: indexing, abstracting, classification, thesauribuilding, subject-heading-work, document selection, development of interest profiles, and a number of other similar activities. In a very real sense, information science activities making use of the conceptualization process encompass and represent some of the major intellectual contributions to the field.

We can seek to study and analyze the process of conceptualization; we can seek to apply this process to the field of information science; we can develop adequate curricula to cover the Conceptualization Segment of the information science field. However, we cannot undertake to evaluate the degree of ob- jectivity of concepts stemming from the application of this subjective process in other disciplines. Concepts are frequently verbalized, they are represented in some notational system and are recorded in some manner for storage and transmission in the form of symbols and signals. It must be reiterated, however, that when we are investigating the conceptual attributes of the interpretation of symbols and signals, whether conceptualized, coded, and transmitted by information scientists or by others, we are dealing with "information," i.e., representations of subjective notions which, as already implied, do not lend themselves to sustained and rigorous scientific investigation and proof. Except for a moment in time and space, and except as interpreted by a single individual, our prime variable to be investigated is consistently inconsistent. As is the case in other social sciences, the application of statistical techniques and normative survey methodology may yield results which, at best, would be approximations. Classic decision theory may reduce the uncertainty of the results, but empirical proof, the kind of proof that we associate with the better-recognized scientific disciplines, cannot be derived through investigation of the Conceptualization Segment of the information science field. A scientific theory of information, it would seem, can be developed only by completely ignoring human conceptualization, human evaluation of information.

\section{The Storage/Transmission Segment}

Information science can and does concern itself with the physical attributes of symbols and signals, their production, storage, transmission, and manipulation. This segment of information science is here labeled as the Storage/Transmission Segment. In his work on communication theory, Shannon defined the term 
"channel" as the medium used to transmit a signal from transmitter to receiver. ${ }^{5} \mathrm{He}$ also noted that the semantic aspects of communication are irrelevant to the engineering aspects. Thus, investigation of the physical attributes of symbols and signals, their production, storage, transmission, and manipulation can indeed entail more objective analyses through employment of experimental techniques and the frequent application of research methodology capable of providing empirical proof. What our curricula and information science investigations would seek to emphasize here would be the means of storing and transmitting symbols and signals; we would be concerned with analyses of the storage/transmission channels, their networks, their efficient organization and administration, but not with that which is transmitted, i.e., the information itself. We could certainly develop curricula to cover this segment of information science.

We need to pause here, however, and resolve a fundamental question: Should not information science delimit its interests to those symbols and signals which have a direct bearing on the transmission of previously recorded information, i.e., document-stored discourse? Stated a different way, should we not concern ourselves at present with those communication channels which permit crossing the barriers of both space and time, i.e., providing capability for both storage and transmission. Thus, for example, telephonic communication, crossing as it does the barrier of space, or interpersonal communication accomplishing a similar objective, would be of vital interest to us, but not as ends in themselves. Rather they would be of interest to us only as channels for the transmission of a more permanently stored and

\footnotetext{
${ }^{5}$ Claude E. Shannon and Warren Weaver, The Mathematical Theory of Communication (Urbana, Illinois: University of Illinois Press, 1962), p. 5.
}

organized data base of recorded discourse. Our interest in the application of single channels would be no different from that of the physician making use of the telephone or interpersonal communication to communicate with the hospital or his patient. Essential communications channels? Yes! But peripheral at present to the study of information science.

The phonodisc, the cuneiform tablet, the computer tape or the magnetic disc, the full-size manuscript, and the text or its microform can be viewed as storage/ transmission channels capable of transcending the barriers of both time and space. A single concept may be expressed in a word; it may be stored and reduced as a coded symbol or signal; it may be expanded and recorded as a sentence, paragraph, single text or collection of texts which may, in turn, be organized into a library or library network. Storage/transmission channels, up until the last several decades, have been confined for the most part to the codex or printed text. In a broad sense, individual documents, or as they are organized into libraries and information centers, can be considered to be storage/ transmission channels providing a link through time and space between that which has been conceptualized and recorded in the past throughout the world, and the user of today, wherever he may be located.

Doubtless when the Taylor and ASIS information science definition states in part that information science is to investigate "the technology necessary to process information," what is implied are investigations relevant to the Storage/ Transmission Segment of our occupational field.

\section{The Utilization Segment}

Without a doubt a major portion of activities engaged in by libraries and a major portion of library school curricula 
have been and are currently devoted to the "technology necessary to process information." The scientific method and experimental techniques have been frequently applied internally within a single library or in a more general way by such organizations as the Library Technology Program of the American Library Association, by various committees in carrying out projects for other professional library associations, as well as by individual professional librarians in their quest for developing "technology necessary to process information." However, the Taylor and ASIS definition of information science does not stop with the goal "to investigate technology necessary to process information." The definition goes further in its aim, i.e., "to investigate technology necessary to process information for optimum accessibility and use" (emphasis supplied). Optimum accessibility and use-by whom?-by machines?-by humans?

For if the definition implies, as one interpretation seems to imply, optimum accessibility and use by humans, then we are clear out of the Shannon sphere of investigation of physical attributes of storage/transmission channels. We are once again confronted with subjective notations which, as a group, have been here labeled as the Utilization Segment of the information science field. Here we can identify and group such activities as relevance assessment, management appraisals, evaluation of community satisfaction or the satisfaction of national or international cultural, ethical, recreational, or socio-political goals. Again, we can develop curricula to deal with the subjective notions relevant to this segment of information science.

\section{Conceptual Framework FOR INFORMATION SCIENCE}

On the basis of accepted and prevailing definitions for the field of informa- tion science and the understanding developed here of the elements comprising the field, we are concerned with the segments of:

\section{Conceptualization \\ 2. Storage/Transmission \\ 3. Utilization}

Two of the above segments, namely Conceptualization and Utilization, can be investigated only through the analysis of subjective notations, leaving us with little likelihood of obtaining corroborative empirical proof for whatever findings may be derived through the employment, for the most part, of statistical or normative survey methodology. While experimental methodology and the scientific method in general can be applied, many variables that are central to the conceptualization and utilization segments cannot at present be identified, let alone isolated, and many decades may elapse before even some of the variables may be rigorously studied.

Perhaps, however, we should backtrack for a moment. Rather than assume that the segments discussed above comprise the information science field, perhaps our earlier declarative statements should be rephrased to the form of a question: Do they comprise the field? For if we were to get agreement on this generalization, on the basis of such an agreement we could, perhaps, start putting together many of the pieces within the information science realm which have been kicked about within the last several decades. We could, perhaps, begin to develop curricula for information science in harmony with the overall conceptual framework for the field. We need to be cognizant of the fact that there is fractionalization, there is animosity, there is distrust in our field. Continued exacerbation, continued division can lead only to disaster. The struggle between the science information officer and the librarian in Great Britain re- 
sulted in considerable harm to both. Deliberate fractionalization, organizationsponsored animosity between librarians, documentalists, information scientists, information specialists, or to add some new designations, knowledge transfer professionals, or social change agents will not promote the advancement of the field of information science.

It is quite understandable that a particular institution, whether in the name chosen for that institution or whether in its curriculum content, should place emphasis on one rather than another segment of the information science field. It is understandable that a school, such as Columbia University, considering at one time the service or utilization aspect to be highly important, should name its institution the School of Library Service. It is understandable that the State University of New York at Albany, considering the "science" aspect important, should call its school the School of Library Science. It is even understandable that certain schools should seek to make the best of two worlds and call their institution the School of Library and Information Services $^{6}$ or School of Information and Library Studies. ${ }^{7}$ What appears to be not understandable or not acceptable is to define information science as being comprised of only one of these segments, of championing and elevating one of the segments through the destructive denigration and detriment of the others. It may not be improper to note that allegations such as those found in the Taylor letter and ASIS literature that "information science as a discipline has as its goal to create and structure a body of knowledge, technology, and systems relevant to the information transfer chain" and that "ASIS is the only association in this

\footnotetext{
- Maryland University. School of Library and Information Services. Bulletin (College Park, Maryland: University of Maryland, 1968).

${ }^{\tau}$ State University of New York at Buffalo. School of Information and Library Studies. Preliminary Bulletin (Buffalo, New York: SUNY at Buffalo, 1968).
}

country consciously dedicated to this objective" is, I feel, disruptive, to say the least. As past chairman of the SLA Documentation Division, the author has had the not so pleasant task of blunting the damage of such paper missiles. Perhaps we should have done what has been done in the USSR; i.e., adopt the term informatics rather than information science to reflect more adequately the theoretical, applied, and social aspects of our field. ${ }^{8}$

While drastically revising existing curricula, while formulating new curricula, we need to remember that, according to the most recent Bowker Annual, during 1967 there were more than 24,000 libraries in the United States, employing in 1965 close to 81,000 librarians. A total of 334 institutions were offering training in librarianship (including forty-one ALA accredited library schools) and were awarding annually more than 6,000 bachelor's or higher degree in librarianship. ${ }^{9}$ Like it or not, these individuals and these institutions are a part, and a substantial part, of the information service system. We need to upgrade and devise new curricula and continuing education curricula for them as well as for the new student or the newly organized school of information science. It will do little good to denigrate past achievements of librarians, to exaggerate falsely the attainments of information scientists, or to set unrealistic goals, unrealistic prerequisites, and impossible areas for future investigation. While without a doubt that mathematics will become increasingly essential in this field, let us keep in mind that information science, as observed by Fairthorne, a mathematician and information scientist in that order, is at present pre-mathematical and that its basic principles have not been discovered, let alone formulated

${ }^{8}$ A. I. Mikhailov, and others. Osnovy Informatiki (Moskva: Izd-vo Nauka, 1968), 756p.

9 The Bowker Annual of Library and Book Trade Information, 1968 (New York: R. R. Bowker Co., $1968)$, p. $6,313-16$. 
so strongly that mathematics can be used to explain the phenomena. ${ }^{10} \mathrm{We}$ need to recognize that we cannot all, indeed we should not all, train to become systems people; that all three segments of the information science field need representation in the curriculum; that the humanist as well as the technologist can make worthwhile and significant contributions to this field. Practice, as in medicine, long preceded theory. Until theory is formulated, we need to pool our resources, we need unity of purpose, we need broadness of vision. A quote from Bertrand Russell may be in order here.

\footnotetext{
${ }^{10}$ Robert A. Fairthorne, "Mathematics, Mechanics, and Statistics for the Information Science Curriculum, or What Mathematics Does an Information Scientist Need?" American Documentation Institute. Proceedings, 26th Annual Meeting, Chicago, Ill., October 1963 , p. 39 .
}

In his text, Human Society in Ethics and Politics, Russell notes that:

Modern science and technique have enhanced the powers of rulers, and have made it possible, as never before, to create whole societies on a plan conceived in some man's head. This possibility has led to an intoxication with love of system, and, in this intoxication, the elementary claims of the individual are forgotten. To find a way of doing justice to these claims is one of the major problems of our time. ${ }^{11}$

The field of information science is concerned with the study of both men and machines. I submit that our orientation and curricula need to reflect this fundamental truism.

11 Bertrand Russell, Human Society in Ethics and Politics (New York: American Library, 1955), p. xv. 